\title{
Improving transfer of learning through designed context-based instructional materials
}

\author{
Michael Allan A. Bahtaji \\ Physics Department, Technological University of the Philippines, Manila, Philippines \\ For correspondence: michaelbahtaji@gmail.com
}

\begin{abstract}
This study investigates the outcome of designed source-text materials in context-based physics learning using validated test questions in mechanics. Two groups of students received context-based instruction (experimental group) and one group received content-based instruction (control group). These three groups of students are only different with the (designed and un-designed) source-text materials. The mean-frequency of scores was compared. Furthermore, students were given achievement test and transfer-test. The scores from these two tests were correlated. In general, the results showed that additive source-text materials in context-based instruction significantly improve the performance of the student in mechanics.
\end{abstract}

Keywords: context-based learning, content-based learning,

\section{Introduction}

\section{Context-based learning in Physics}

Instruction in physics become commonly executed using content-based instruction that result into realization on the importance of connecting physics into real life experiences, this situation prompted to suggest a more dynamic and interactive approach that improve problem solving skills of the students in physics which is the context-based learning (Whitelegg \& Parry, 1999). The present content of the physics curriculum become unsupportive to the interest of the students, thus the content of the present curriculum does not provide a huge impact to the life and career of the students. Bringing up the role of context-based learning becomes challenge to the present problem this provide encouragement to make a step into the new pedagogy of teaching science from the content science teaching at present.

Context-based science education was designed to consider it significant and relevance to all students (Hooreman, 2008). During the learning process, it is not required for the student to focus more attention on static theoretical content regarding concepts and memorizing procedural method in solving problems in physics (Bennett, Lubben, \& Hogarth, 2006). Instead, it is intended to acquire understanding about the importance of physics into the society and how technology link to provide common problems encounter in life. The learning process start by letting students experience physics during the instruction, this include active interaction that allows sharing of ideas about problems in the society commonly encounter and thinking for a best solution using concepts and principles of physics.

The present way of delivering lesson to the students, focus traditionally in a content-based learning that consist of too much content that usually difficult for students to undergo processes such as selection process, analogical process, and organizational process, these processes are essential for transfer effect of concepts, principles, and skills of the students (Van Bragt, 2010). A revised context- 
based learning curriculum provide more emphasis on creating new concepts in physics based on the ability of the student in integrating real life experience on the physics content. The structural form of context-based instruction include skills in integrating physics concepts by relating physics learning to problems commonly encountered by the students in the society and creating skills that will give answer and solution to social problem (Koopman, 2010). Thus, student are encourage to develop problem solving skills prior to their ability to identify problems usually encounter or experienced in the community. During the learning process, facilitating context-based learning include integration process of physics content to social life activities of the students, in this process, student can develop their skills in relating physics in to their life that allows students to contribute solution and answer to many problems students encounter in the society, this include technological output which will improve the life of the people or theoretical model that will guide people to achieved competency in their professions. The most relevant topic related with and in coherence with the prior knowledge of the student is the focus of the context-based physics instruction which goal is to help student develop integration process of physics concepts into their social experience (Rajuan, 2008). The process is related with the idea "need-to-know" method that utilized selection process of significant topics and content in physics. The method of "need-to-know" structured the mind of student to physics concepts, to problem solving skills, and to physics principles which becomes best when student perform analogical skill based on the structured and organized physics concepts into the mind of student. The conception and problem solving skills of the student are encourage to enhance during the instruction in the context-based designed curriculum that aim to improve the skills of the students in integrating experienced to the study of physics (Mittendorf, 2010). The output of student's prior knowledge derived from the analogical skills of the student is the first step in the context-based learning process, the result is a structured and organized understanding of physics concept which can be used to solve problem correctly. The transition from misconception to true conception occur during integration process this include students ability to relate prior knowledge into selected useful concept in physics, thus student ability to create coherent understanding result into the transition from wrong physicsconception to correct physics-conception (Luecken \& Parchmann, 2006). It is said that, conditioning the mind of the learner through coherent and structured physics learning during context instruction result into productive output either in the field of technology or in the construction of model theoretically.

\section{Source-text in Context-Based Instruction}

The common learning situations that include lectures and demonstration in physics instruction used different instructional materials like multi-media and real objects that increase the transfer of information from the person authority to the students (Crasborm, 2010). The information gained from content-based instruction does not retain in to the long term memory of the student and becomes weak regardless with the concepts and problem solving skills of the student (De Bakker, 2010). Although, the present way of physics instruction enhance selection process and analogical process in the mind of the student it was proven that additive task like presentation of source-text materials that support context-based instruction will result into a more better learning in thermodynamic. The designed source-text was structured with the main objective of the context-based learning. Whereas, the content of the designed source-text materials in physics does not only provide theoretical explanation and problem related concepts but importantly, it include common real life situations encounter by the students in the society. The content of the source-text material provide situations that will provide greater opportunity to the learner to think critically and improve problem solving skills in solving problem. In a given topic like "heat transfer", it is characterized that heat can be measured quantitatively using the calorie and joules as a unit of heat, with regard to this, it is appropriate to provide real life situation commonly encountered by the student in their life, like for example the activities in the kitchen that involve heat transfer such as cooking of foods or cooling of foods, these activities, students usually see and experience outside the school could be one good example of relating physics content activities outside the school. The situations presented in the source-text materials consist of three to five situation arranged from ascending order from simple situation 
student experienced in to real life situation up to situation which is more complex and dynamic. An example of complex and complicated situation is the explanation on how heat transfer process in the car's engine, how heat process from a nuclear power plant and many more (Vos, 2010). Thus, the situation presented in the source-text materials provide situations arranged from the most basic situation commonly encountered by the student in the society up to a more complex and complicated situation. In this experiment, it is expected that in the first given situation, student can related present knowledge in terms of the situations given in the source-text into the physics content during the instruction. The end process of this source-text activity allow student to develop analogical process as a solution to a more complex and harder problem as given from the higher situations given in the source-text (Rohaan, 2009). Lastly, the final process involves organizational process of knowledge and concept gained by the students after they received the instructional material.

\section{Methodology}

\section{Participants}

To determine the outcomes of students' performance in the achievement test and to provide empirical data on how designed context-based instructional materials enhance the performance of the students in physics, three groups of students were utilized in the study. 39 students taking-up Bachelor of Science in Information System (17 male, 22 female, mean age $=20.02$ years, SD=2.07), 35 students in Bachelor of Science in Computer Education (15 males, 25 females, mean age of 19.80 years, SD=1.87), and 41 students taking-up Bachelor of Secondary Education in Home Economics (11 male, 30 female, mean age 20.34 years, $\mathrm{SD}=1.78$ ). Three groups of students with un-identical courses were experimented to determine whether scientific literacy or context-based learning have affected the performance student in physics.

\section{Procedure}

Three groups of participants were randomly assigned with three materials containing designed and un-designed context-based and content-based activity after the instruction, the activity were given 60 minutes each for completion. To find-out if students read and comprehend the activity assigned after the instruction, they were asked to answer designed test presented at the end of the activity. During the activity, the time allotted for each group was followed strictly, thus the mean amount of time required for perfect performance in the activities was the same in all three groups. After the completion of the activity, all the participants were presented with 30 items designed test questions with 30 minutes time interval allotted to finish the test.

\section{Result and Discussion}

\section{Designed context-based instruction}

The result of the designed context-based test, after students were subjected into context-based learning is shown in the table 1. The comparison is reflected by the mean score gained in the test while the standard deviation indicates how individual scores is scattered. The highest mean frequency was attained by the information system students (34.31), the second mean scores was attained by the computer education students (30.57), while the least mean score was attained by students in home economic education (15.35). Base on the data it was observed that context-based instruction is useful for students in information system and students in computer education but contrary to it, not to the home economic education students. 
Table 1. Mean score and the standard deviation in the context-based instruction

\begin{tabular}{lccc}
\hline \multicolumn{1}{c}{ Course } & Mean & $\begin{array}{c}\text { Standard } \\
\text { deviation }\end{array}$ & $\mathrm{N}$ \\
\hline Bachelor of Science in Information system & 34.31 & 6.135 & 39 \\
Bachelor of Science in Computer education & 30.57 & 5.279 & 35 \\
$\begin{array}{l}\text { Bachelor of Science in Home economic } \\
\text { Education }\end{array}$ & 15.35 & 4.693 & 41 \\
Total & 38.08 & 5.369 & 115 \\
\hline
\end{tabular}

The highest standard deviation (6.135) was attained by the information system students the high standard deviation indicates that most of the scores have higher distance with the average scores attained in the test which might be due to individual differences in the context-based learning. The low standard deviation (4.693) attained by the home economic students indicate common similarity on students technique in dealing with the instruction. The low standard deviation shows homogeneity of the scores.

\section{Un-designed context-based instruction}

An activity that introduced different topic in kinematics which introduce concept about motion was introduce in the class. Although context-based instructions were integrated during the discussions, the problems shared by the students were slowly link to the topic because of the un-designed contextbased instruction, unlike with the designed context-based instruction, topics, subtopics and terms were classified in order and groups in order to provide students hint on how they can relate their experience to the lesson. To determine how students responded through a condition in which terms, topics and subtopics were not designed and classified orderly to favor context-based learning, the mean scores and the standard deviation of the three courses were compared. Table below showed that the highest mean scores was obtained by the students in information system (30.33), the second mean score was obtained by the students in computer education (28.11), while the least mean scores was obtained by the students in home economics education (18.08). The highest mean score obtained by the information system students might be due to their strong experience in the field of science and mathematics in which most of the students credit lot of subject in science and mathematics while those group of students who gained less in the mean score credit few subjects in science and mathematics as a requirement for their course.

Table 2. Mean score and the standard deviation in the un-designed context-based instruction

\begin{tabular}{lccc}
\hline \multicolumn{1}{c}{ Course } & Mean & $\begin{array}{c}\text { Standard } \\
\text { deviation }\end{array}$ & $\mathrm{N}$ \\
\hline Bachelor of Science in Information system & 30.33 & 5.278 & 39 \\
Bachelor of Science in Computer education & 28.11 & 3.657 & 35 \\
Bachelor of Science in Home economic & 18.08 & 4.079 & 41 \\
$\begin{array}{l}\text { Education } \\
\text { Total }\end{array}$ & 25.51 & 4.338 & 115 \\
\hline
\end{tabular}

Among the three group the highest standard deviation (5.278) was obtained by the students in information system which indicate a far distance of individual scores to the mean scores and this might be due to differences in how students process knowledge during the activity, in the other hand, the low standard deviation obtained by the students in computer education (3.657) and home economic students (4.079) show a homogeneity on the scores. 


\section{Content-based learning}

The control in this experiment was done using a content-based instruction that focus more on the content of the syllabus of the subject matter rather than the applications and integration of student's real-life experiences to the lesson. This classroom activity includes board lecture, question and answer portion and board work problem solving. The content-based instruction contains the same topic in kinematics but do not include active integration of student's real life experience to the topic discussion or to the lesson. The method used in the analysis of this result was the same with the method used in the two condition presented earlier. The high means score of the students in information system (24.82) predict the processing ability of the student that include content knowledge students used on the lesson introduced to them. It was followed by the mean scores of the students in computer education (22.57) which could also related to the ability of the students to process concept, and lastly, the least among the group is the mean scores of the students in home economic education (16.85). According to Panek (2012), the ability of the students to process information in content-based learning is strongly related to the ability of the students to process conceptual understanding.

Table 3. Mean score and the standard deviation in the content-based instruction

\begin{tabular}{lccc}
\hline \multicolumn{1}{c}{ Course } & Mean & $\begin{array}{c}\text { Standard } \\
\text { deviation }\end{array}$ & $\mathrm{N}$ \\
\hline Bachelor of Science in Information system & 24.82 & 4.773 & 39 \\
Bachelor of Science in Computer education & 22.57 & 5.091 & 35 \\
Bachelor of Science in Home economic & 16.85 & 4.753 & 41 \\
$\begin{array}{l}\text { Education } \\
\text { Total }\end{array}$ & 21.22 & 4.877 & 115 \\
\hline
\end{tabular}

The heterogeneity of the scores is reflected on the standard deviation on the scores of the students in information system, the result of the mean score can be correlated to the standard deviation of the said students. The result indicate that a high standard deviation of the said students predict the heterogeneity of the scores of the students and the uniqueness of individual thinking ability of the students affect the result of the mean scores, in the other hand the low standard deviation of the students in computer education and home economics education is also related to the result of the mean scores of the students, thus the homogeneity of the scores show common thinking ability among the students which resulted to a low standard deviation.

\section{Comparison on the three condition of activity}

The participants of the study were experimented into three conditions to determine how student's response to the designed instructional materials used in the experiment. In the first set of activity, designed context-based instructional materials were utilize in the activity then evaluated using the transfer test. On the second stage of the experiment, an activity using a concept source was introduced to all the four groups but without the use of designed context-based instructional materials (ungroup concept and topics), then evaluated again for its effect using the transfer test. In the final stage of the activity a pure content-based instruction were experimented to the students and this serve as a control variable in the experiment. To distinguish how the three stages of activity affect the performance of the students in the experiment the mean scores of the students obtained from the transfer test were presented and compared in the table below. 
Table 4. Mean scores in the three conditions

\begin{tabular}{lcc}
\hline \multicolumn{1}{c}{ Activity } & Mean & Standard Error \\
\hline Designed context-based & 23.739 & 0.36 \\
Undersigned context-based & 22.440 & 0.36 \\
Control & 20.370 & 0.36 \\
\hline
\end{tabular}

The activity that gained the highest mean scores was the activity that integrate context-based learning with the use of designed context-based materials in the experiment which gained a mean score of 23.739, this activity encourage students to share their experience and encourage them to relate their sharing about the topic. In this instruction, students were encouraged to classify their concept using the designed text. The activity that integrates context-based learning but do not include designed context-based materials gained a mean score of 22.440. In the other hand, the activity which serve as a control group emphasize more on the content of the subject matter instead on the application and integration of the subject matter into real-life situation, gained a mean score of 20.370, this mean score is the least among the three method. According to Hogarth (2006), student's positive attitude toward physics motivates them to pursue intensive lesson in the subject.

\section{Comparison of the three different courses in the experiment}

Three different courses were chosen to determine how they responded to the three method of instruction that utilize context-based learning and content-based, the test that evaluate how students acquired conceptual change or how students organized prior knowledge to construct a more precise solution to the problem were evaluated using the content test which was been constructed before the experiment were presented to the students. In connection with the main objective of the study, three courses were chosen with different field of study and specialization so that the comparison and differentiation to which group of student utilized context-based learning in solving problem in physics. These three courses were categorized into the group of students who have strong background in science and mathematics and mostly use problem solving technique in solving problem in physics, these two courses that have strong background in science and mathematics and credit many subject in science and mathematics. In the other hand the two courses which their field of specialization do not focus in science and mathematics but more practical skill education are categorized as the group of students whose background in science and mathematics is not that strong enough and do not usually expose to science related problems, this course is the home economics education. The comparison of the three courses were summarize in the table below.

Table 5. Comparison of the mean scores of the three courses

\begin{tabular}{lcc}
\hline \multicolumn{1}{c}{ Courses } & Mean & Standard error \\
\hline Bachelor of Science in Information system & 29.821 & 0.416 \\
Bachelor of Science in Computer education & 27.081 & 0.427 \\
Bachelor of Science in Home economic & 16.758 & 0.411 \\
Education & \\
\hline
\end{tabular}

The univariate general linear model computation was done to compare the mean of the three courses, and base on the result, those students who gained the highest mean score is the course in information system (29.821), followed by the mean score of the students in computer education (27.081), the least mean scores was obtained by the home economics students (16.758). According to Duit (2003), the students ability to process knowledge in problem solving is related to the prior ability of the students acquired from the earlier study or to their exposure to a certain particular knowledge and it was stated 
in the study that those student who have strong exposure in the study of science and mathematics gained the highest mean scores as the result of the activity presented to them, in the other hand, those students who have a small experience and exposure to science and mathematics gained the least mean scores in the transfer test and content test.

\section{Pearson r Correlation}

The used of context-based instruction in physics become very effective if it is guided with proper designed of context-based instructional materials that will increase students interest to pursue further study in the field of science and mathematics, the method of "need to know" encourage students to process and analyze information that is only needed and essential to the student and to its society, this will help students to form analogy and solution to many problem or answer to many questions. This technique of integrating real-life experience to the content of the lesson will improve the problem solving skills of the students.

To determine the role of designed context-based instructional materials on the performance of the students in physics, the transfer test scores and the achievement test scores were compare using the linear regression. Studies found out that students' ability to identify problem related topic to the lesson is moderately correlated to the ability of the students to solve problem in physics (Parchmann and Luecken, 2010. The entered variable is the scores of the students in information system in the transfer test and the content test.

Table 6. Mean and standard deviation of the scores in the transfer test \& the achievement test

\begin{tabular}{cccc}
\hline Descriptive statistics & Mean & $\begin{array}{c}\text { Standard } \\
\text { deviation }\end{array}$ & $\mathrm{N}$ \\
\hline content test scores & 28.50 & 6.69 & 157 \\
Transfer test scores & 23.48 & 10.08 & 157 \\
\hline
\end{tabular}

The mean scores in the content test and transfer test of the students who undergo active construction of graph are 28.50 and 23.48. While the standard deviation of the content test and transfer test are 6.69 and 10.08. Although the mean scores of the two tests are near to each other the standard deviation of the transfer test is higher than the standard deviation of the content test which indicates that the scores in the transfer test are more homogenous compare to the content test. Studies found out that students' ability to identify related problem regarding the content of the lesson is related to the ability of the students to solve problem (Pilling, Waddington, and Holman, 2001). The entered variable is the scores of the students in information system in the transfer test and the content test.

Table 7. Pearson correlation of the achievement test scores and the transfer test scores

\begin{tabular}{crrr}
\hline \multicolumn{2}{c}{ Correlations } & \multicolumn{1}{c}{ ATS } & \multicolumn{1}{c}{ TTS } \\
\hline Pearson & ATS & 1.00 & 0.353 \\
Correlation & TTS & 0.353 & 1.00 \\
Sig (1-tailed) & ATS & & p[0.05 \\
& TTS & p[0.05 & \\
N & ATS & 115 & 115 \\
Note: ATS (Achievement test scores), TTS (Transfer test scores)
\end{tabular}

Statistically, the Pearson-r correlation was utilized to determine the relationship between content test scores and the transfer test scores. The computed value of $r(0.353)$ indicates a moderate correlation between the two sets of scores. Since the information and skills gained from the context-based instruction were utilized in testing, highly correlation indicates a strong correlation between the two 
variables while a low correlation indicates a weak correlation between the two variables, in the other hand the two set of variable were significant at .05 level of significant based on the two tailed test of comparison between the means score of the transfer test and the mean score of the content test in the total 157 participant used in the experiments. The square of the computed Pearson correlation is 0.124 were multiplied to one-hundred, this will identify the percent of the total population used in the study that explain the scores in the transfer test predict the scores in the achievement test. Thus $12 \%$ of the total sample can explain that the scores in the transfer test predict the scores in the content test.

The standard error which is 6.28 indicates the distance between the estimated scores to the actual scores, thus greater distance between estimated scores and the actual score indicates a higher standard error while a lesser distance indicates a smaller standard error.

The linear equation $y=m x+b$ was utilized in the linear regression, the value of $y$-intercept $(y=23)$ in the regression line show that, student attained a score of 23 in the content test when the students attained zero in the transfer test. The value of the slope $(=0.23)$ is the constant value which is 0.23 , this indicate that in every one point gained in the transfer test, the scores of the students in the content test will increase into 0.23 . The standard error for $y$-intercept (1.27) is higher than the standard error of slope (0.05) which indicates a higher distance of actual score to the estimated scores.

Table 8. slope and the y-intercept

\begin{tabular}{ccccc}
\hline Model & B & $\begin{array}{c}\text { Standard } \\
\text { Error }\end{array}$ & $\mathrm{t}$ & Sig \\
\hline Constant & 23.0 & 1.27 & 18.04 & p? 0.05 \\
TTS & 0.23 & 0.05 & 4.69 & p 0.05 \\
\hline Note: TTS (transfer test score), SE (Standard error).
\end{tabular}

The frequency and the regression standardized residual were plotted, were in, the mean of the regression standardized residual is set into zero while the standard deviation were set into 1 , the structured of the graph give emphasis on the moderate correlation between the scores in the transfer test and the scores in the content test.

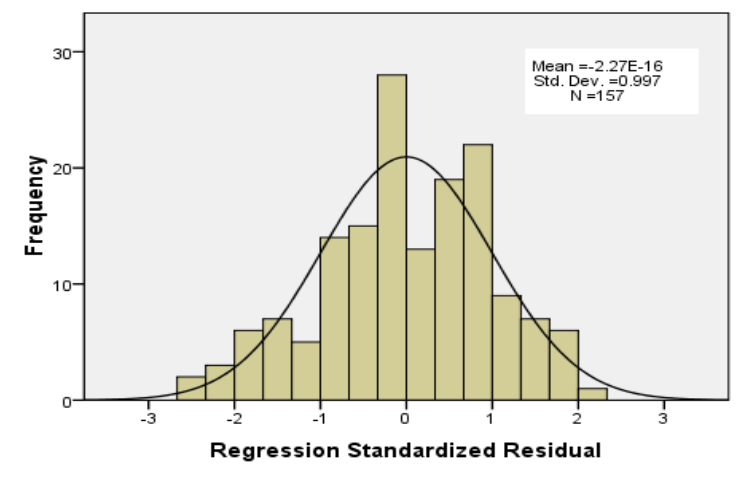

Fig. 1. Frequency and regression standardized residual

The linear correlation were presented in the regression standardized residual and regression standardized predictive value in the plot were we can see the small variation on the student who gained in the transfer test but did not gained in the content test, the same also with the other side-part of the graph which show a small variation on the students who gain in the content test but did not gained high in the transfer test. At the middle, there are higher number of dots which best explain the relationship between the two variables. 


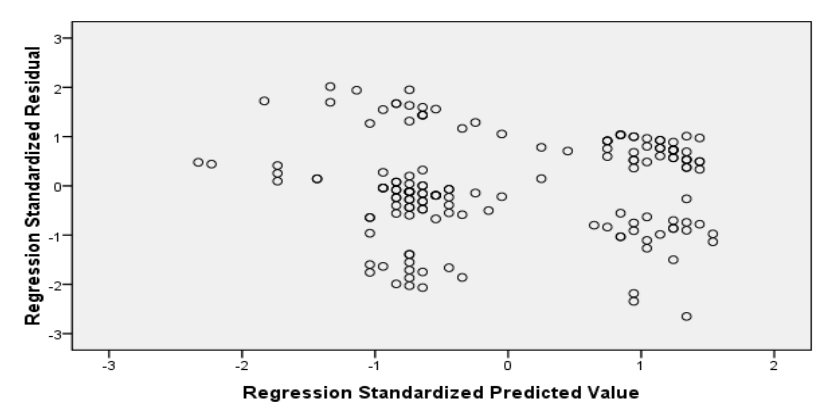

Fig. 2. RSR and the RSP graph

At the middle, there are higher number of dots which best explain the relationship between the two variables which was been indicated by table 7 . The result of the study indicate that context-based learning motivate students to open real-life experience to the classroom activity and discussion, although students subjected into context-based learning become active in the class participation and class interaction, students ability to connect shared experiences to the lesson is not develop to students. Physics learning include skills in problem solving, to make this possible, students should practice proper skills and procedure in identifying problems which will contribute into society, if in case solve by the students, thus, effective learning indicate how students practice the proper skills in identifying problem, skills in relating the problem to the content of the syllabus, and lastly skills in solving the problem

\section{Conclusion}

The problem stated earlier were answered in the analysis section, and the result from the computation show that designed context-based learning play an important role in fostering source processing in solving problem in physics. The substantial correlations between the transfer test and the achievement test in the study suggest that context-based learning activate students processing in learning the lesson. . The correlations are in line with the assumption that, by designed context-based learning, learners may encourage to pursue studies in the field of science, thus, relating student's real-life experience to the lesson enhance the learning processing of the students.

Although, the study indicate that context-based learning increase the performance of the students in transfer test and achievement test, the scores of the students increase much higher when learning using context-based instruction were properly design. Students, engage in the used of designed context-based instructional material improved student's skills in connecting the problem to their lessons. The skills of the student in integrating real-life experience to the lesson were due to proper classification and organization of the topic in physics during the instruction. Thus, organizing terms and topic content help student to classify the situations into its proper physics concept shared by the students during the instruction. Thus, the results showed that additive source-text materials in context-based instruction significantly improve the performance of the student in mechanics.

\section{Acknowledgements}

I thank the students, teachers, and deans of the Technological University of the Philippine in manila for their support in running the study.

\section{References}

Bennett, J. Lubben, F. \& Hogarth, S. (2006). Bringing science to life: A synthesis of the Research Evidence on the Effects of Context-Based and STS Approaches to Science Teaching. Wiley Inter Science, 91, 347-370

Crasborm, F.J.A.J., Hennissen, P.P.M.(2010). The skilled mentor. Mentor teachers' use and acquisition of supervisory skills. De Bakker, G. M.(2010). Allocated online reciprocal peer support via instant messaging as a candidate for decreasing the tutoring load of teachers. 
Hooreman, R.W.(2008). Synchronous coaching of trainee teachers: An experimental approach.

Koopman, M.(2010). Students' goal orientations, information processing strategies and knowledge development in competencebased prevocational secondary education.

Luecken, M. \& Parchmann, I. (2010). Context-based Learning for Students and Teachers: Professional Development by participating in school innovation projects. Leibniz Institute for Science and Mathematics Education, 38, 131-137.

Mittendorf, K.M.(2010). Career conversations in senior secondary vocational education.

Rajuan, M.(2008). Student teachers' perceptions of learning to teach as a basis for the supervision of the mentoring relationship. Rohaan, E.J.(2009). Testing teacher knowledge for technology teaching in primary schools.

Van Bragt, C.A.C.(2010). Students' educational careers in Higher Education: a search into key factors regarding study outcome. Vos, M.A.J.(2010). Interaction between teachers and teaching materials. On the implementation of context-based chemistry education.

Whitelegg, E. \& Parry, P. (1999). Real-life context for learning physics: Meanings, issue and practice. Teaching Physics, 32, 12-15 